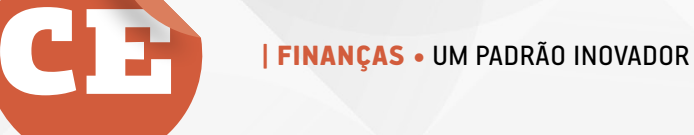




\section{UM PADRÃO INOVADOR}

| POR EDILENE SANTANA SANTOS

\section{A convergência para um modelo internacional único de contabilidade vem transformando, para melhor, as informações financeiras das empresas brasileiras.}

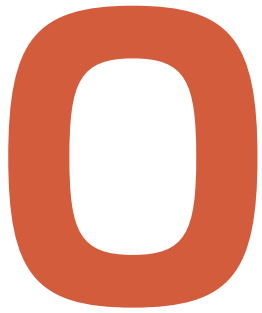

processo mundial de convergência para um padrão internacional único de contabilidade (que hoje abrange 150 países) chegou plenamente ao Brasil em 2010. Todo o conjunto de normas internacionais (International Financial Reporting Standards - IFRS) passou a vigorar no país para as empresas de capital aberto, de grande porte e, atualmente, para as médias e pequenas. Jornalistas especializados, analistas e acadêmicos avaliaram essa convergência como capaz de provocar mudanças intensas, com potenciais ajustes contábeis "milionários" e até uma "revolução" nas organizações brasileiras, o que exigiria um longo caminho para assimilação.

\section{MOVIMENTO DISRUPTIVO}

Por que o padrão IFRS constitui uma transformação tão profunda no Brasil? A resposta, conforme estudos internacionais realizados desde o início da globalização (segunda metade do século XX), reside na diferença entre as tradições culturais e legais que deram origem ao sistema contábil brasileiro e as que incorporam o novo padrão. O sistema legal brasileiro, assim como o dos países de influência eurocontinental, tem sua origem no direito romano (civil law ou code law), que norteou o desenvolvimento de uma contabilidade formalista e fiscalista. Houve foco predominante na minimização dos tributos, e não na mensuração da realidade econômica da empresa, com vistas aos investidores.

Em oposição a esse modelo, o direito consuetudinário (common law) inspirou a contabilidade nos países de influência anglo-americana. Havia uma contabilidade específica para o fisco, e os profissionais puderam focar na expressão da realidade econômica das transações, o que constitui a base estrutural do padrão IFRS. Compreensivelmente, a adoção do IFRS no Brasil gerou um intenso debate que, com a Lei n. ${ }^{\circ} 12.973$, de 2014, culminou na separação definitiva entre os critérios de mensuração financeira e tributária.

A verdadeira e mais profunda transformação desencadeada pelo padrão internacional consiste em substituir uma postura passiva - que se resume em cumprir literalmente normas detalhistas e restritivas, construídas com predomínio da lei fiscal - por uma postura proativa de julgamento. Princípios e padrões do IFRS são mais abrangentes e dão primazia à essência sobre a forma, com vistas a melhor representar a realidade econômica específica da empresa.

Assim, pode-se considerar que a adoção do IFRS no Brasil, como nos países de influência eurocontinental, significou um choque de tradições contábeis. Houve grandes transformações que, sob alguns aspectos, caracterizaram-se como uma "revolução", reorientando profundamente posturas, hábitos e práticas. 


\section{Princípios e padrões do IFRS dão primazia à essência sobre a forma, com vistas a melhor representar a realidade econômica específica da empresa.}

\section{VANTAGENS DO NOVO PADRÃO}

Supõe-se que a adoção de um sistema contábil diferente da nossa prática tradicional, implicando grandes esforços e consideráveis custos, só teria sentido se trouxesse benefícios relevantes para as empresas brasileiras. O primeiro deles seria fazer com que as demonstrações financeiras das organizações brasileiras fossem comparáveis às das demais empresas do mundo, tornando-as facilmente inteligíveis por investidores, financiadores, exportadores, importadores e outros parceiros e stakeholders na economia mundial.

Mas essa vantagem da comparabilidade internacional não diz respeito apenas às empresas nacionais com atividades comerciais ou financeiras no exterior, mas a todas as demais. De fato, a bolsa brasileira é hoje a quinta maior do mundo, congregando um portfólio expressivo de investidores internacionais que realizam avaliações contínuas das companhias listadas, o que tem impacto, em cadeia, no conjunto das demais organizações e em toda a economia nacional.

O segundo benefício do IFRS é fazer com que as empresas prestem mais informações sobre a natureza de seus negócios ao evidenciar as políticas e os critérios contábeis adotados, bem como os fundamentos dos seus julgamentos. Isso significa um nível mais elevado de transparência, o que beneficia todo o mercado.

Como terceiro benefício, cabe destacar que a adoção do IFRS gera melhoria na qualidade da informação contábil das empresas. De acordo com estudos internacionais, há um aumento da utilidade da informação para o investidor, com maior correlação entre os números contábeis e os valores de mercado (a chamada value relevance da contabilidade) e melhor previsibilidade de resultados pelos analistas do mercado, o que se traduz em maior liquidez das ações e menor custo de captação de recursos. Ou seja, a adoção do IFRS tende a tornar as empresas mais competitivas pelo acesso a capital tanto no mercado interno quanto no global.

\section{UM PROCESSO EM CURSO}

É natural que, apesar de o padrão internacional oferecer grandes vantagens, sua implementação seja um processo de superação de dificuldades arraigadas, sobretudo nos países de tradição latino-germânica de code law.

Por um lado, o próprio espírito do IFRS, derivado da common law, permite certa flexibilidade a características nacionais, desde que preservadas a consistência e a comparabilidade internacional do padrão. Por outro, levantamentos internacionais têm identificado deficiências na assimilação do padrão pelas empresas. Verificou-se que em vários países foi colocado em prática apenas o rótulo IFRS (adoção meramente de jure), sem que as novas normas internacionais tenham sido incorporadas na prática contábil real das empresas (adoção de facto). Mesmo naquelas nações que vêm implementando o IFRS há anos, estudos revelam que ainda persistem insuficiências sistêmicas decorrentes das práticas contábeis anteriores, o que denota que as diferenças culturais permanecem atuantes, mesmo após a adoção do novo padrão.

Nesse contexto, para que a adoção do IFRS produza os benefícios esperados pelas empresas, como mostram pesquisas, é necessário que os reguladores dos diversos países criem instrumentos aptos de controle (law enforcement) que assegurem a efetividade na implementação do padrão internacional.

Um fenômeno talvez mais sofisticado de descumprimento das novas normas tem sido observado por reguladores e analistas na forma de notas explicativas artificialmente avolumadas que, aparentemente, buscam cumprir as normas, mas são infladas com informações pouco relevantes, ao mesmo tempo que escondem dados importantes para os usuários.

Para superar essa deficiência, vários reguladores têm emitido orientações sobre a elaboração de notas explicativas conforme os princípios do padrão internacional. O Brasil foi um dos primeiros países do mundo a regulamentar essa matéria, com a edição da Orientação Técnica OCPC 07 pelo Comitê de Pronunciamentos Contábeis (CPC), aprovada pela Comissão de Valores Mobiliários (CVM) no fim de 2013. Pesquisas recentes no país verificaram que, após a OCPC 07, ocorreu uma diminuição no inchaço das notas explicativas. No entanto, ainda está em estudo a questão de se tal diminuição corresponde a um aumento efetivo da evidenciação (disclosure) de informação materialmente relevante, ou seja, que pode ser realmente útil para a tomada de decisão de atuais ou potenciais investidores e outros stakeholders.

\section{MUDANCAS NA}

\section{FORMAÇÃO PROFISSIONAL}

Desde o início da transição para o padrão internacional, ficou claro para analistas, consultores e reguladores que a 


\section{PRINCIPAIS BENEFÍCIOS DA CONVERGÊNCIA CONTÁBIL INTERNACIONAL}

- Eliminação de barreiras a investimentos internacionais pela comparabilidade da informação.

- Melhoria substancial da qualidade da informação.

- Aumento da utilidade ou value relevance da informação para o investidor.

- Redução do custo de capital.

- Incremento da liquidez das ações.

- Diminuição dos erros de previsão dos analistas de mercado.

- Aumento da competitividade das empresas brasileiras no mercado internacional de capitais.

- Avanço das práticas de transparência das empresas.

- Ampliação da eficiência do mercado de capitais.

- Integração de culturas contábeis, com impacto na globalização do desenvolvimento.

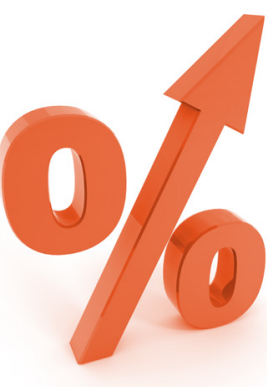

transformação inaugurada pelo IFRS na contabilidade brasileira somente seria bem-sucedida mediante grande esforço de educação e formação profissional, tanto dos preparadores quanto dos usuários das demonstrações contábeis. Posturas e hábitos atávicos precisariam ser reconsiderados e renovados. Novos enfoques e práticas de julgamento sobre reconhecimento, mensuração e divulgação das transações contábeis teriam de ser desenvolvidos.

$\mathrm{O}$ esforço de aprendizagem começou a ser empreendido imediatamente por consultorias, auditorias, escritórios de contabilidade e de advocacia, reguladores, empresas e faculdades. Durante os últimos anos, alguns milhares de profissionais puderam se familiarizar com as novas normas e práticas contábil-financeiras.

No entanto, é preciso destacar que a formação e a renovação dos profissionais envolvidos com as demonstrações financeiras no padrão internacional demandam mais do que o mero conhecimento das normas. Metodologias de ensino-aprendizagem que enfatizem a proatividade na abordagem e a solução de problemas são requeridas para desenvolver as habilidades e competências necessárias. De fato, esse novo profissional precisa não apenas seguir, mas interpretar normas, analisar fatos e discutir políticas e critérios alternativos com os agentes envolvidos para, então, formar seu julgamento sobre como melhor informar as transações da empresa. São competências profissionais, tradicionalmente não enfatizadas, que devem ser desenvolvidas.

\section{ROTEIRO DE SUCESSO?}

Após quase dez anos de introdução do padrão internacional no Brasil, é válido perguntar se o IFRS significa um caminho evolutivo de sucesso, ou se, como ocorre em outros países, ainda não produziu frutos e pode deixar muito a desejar.

Pesquisas comparativas mostram que, apesar das dificuldades encontradas no decurso do processo de implementação do IFRS no Brasil e das deficiências atuais, a adoção do padrão internacional tem produzido melhorias consideráveis na postura e prática contábeis, traduzidas no aumento da qualidade da informação com vistas ao investidor. Já não se concorda tão facilmente com a expressão "meramente contábil" como sinal de dissociação com o mundo real. Pelo contrário, as boas práticas que levam à transparência são consideradas cada vez mais um ativo das empresas.

Levantamentos de consultorias internacionais indicam que, mesmo em meio a crises econômicas e a revelações de fraudes em grandes corporações, os investidores consideram o mercado brasileiro entre os mais atrativos do mundo. Um componente essencial dessa confiança é a evolução da informação financeira no país após a adoção do padrão internacional.

\footnotetext{
PARA SABER MAIS:

Edilene Santana Santos e Laura Calixto. Impactos do início da harmonização contábil internacional (Lei 11.638/07) nos resultados das empresas abertas. RAE-ELETRÔNICA vol. 9, n. 1, 2010.

Edilene Santana Santos, Vera Maria Rodrigues Ponte e Patrícia Vasconcelos Rocha Mapurunga. Mandatory IFRS adoption in Brazil (2010): index of compliance with disclosure requirements and explanatory factors of firms reporting. Revista Contabilidade \& Finanças, vol. 25, n. 65, 2014.

Maristela Girotto. Pesquisas apontam os resultados da adoção das normas IFRS no Brasil. Revista Brasileira de Contabilidade, vol. 45, n. 222, 2016

Philip Brown. International financial reporting standards: what are the benefits?

Accounting and Business Research, vol. 41, n. 3, 2011

Ray Ball. IFRS - 10 years later. Accounting and Business Research, vol. 46, n. 5, 2016
}

EDILENE SANTANA SANTOS > Coordenadora da Linha de Finanças Controladoria do Mestrado Profissional em Gestão para a Competitividade (MPGC) da FGV EAESP > edilene.santos@fgv.br 